\title{
The Role of Baseline Inflammatory Response Biomarkers in Predicting the Prognosis in Non Metastatic Gastric Cancer Patients Treated with Preoperative Chemoradiation
}

\section{Hala Zaghloul ${ }^{1 *}$ and Ahmed Abbas ${ }^{2}$}

${ }^{1}$ Clinical Oncology Department Alexandria University, Egypt

${ }^{2}$ Surgical Oncology Department National Cancer Institute Cairo, Egypt

\begin{abstract}
Purpose: To delve into the prospective of inflammatory-related indicators as neutrophil to lymphocyte ratio (NLR), platelet to lymphocyte ratio (PLR), derived neutrophil to lymphocyte ratio (dNLR), and lymphocyte to monocyte ratio (LMR) in forecasting the clinical outcome for gastric cancer managed with triple modality induction.

Methods: Participants were given two cycles of docetaxel, fluorouracil and cisplatin (TPF), succeeded by radiation (45 Gy) alongside concurrent fluorouracil plus taxotere, then finally surgical resection. The designated baseline prognosticators were linked with clinical-pathological factors. Their contribution to outcome were assessed using Log rank and Cox regression.

Results: The study's analysis revolved around 80 eligible participants. The triple modality induction ensued $22.5 \%$ complete response (PCR) alongside $47.5 \%$ and $42.5 \%$ 3-years estimated overall (OS) and disease-free survival (DFS), respectively. The receiver operator curves (ROC) cutoffs for baseline biomarker were registered at 2.4 (NLR), 1.7(dNLR), 5.1 (LMR) and 130 (PLR). Augmented prognosticators, stage III, R1 resection and >10\% residual tumor were substantially linked to worsened OS and DFS. Interestingly, the augmented dNLR and NLR were self-directed forecasters for deteriorating OS hazard ratio (HR) $2.04(95 \% \mathrm{Cl}=2.41-8.24), 6.63(95 \% \mathrm{Cl}$, 1.61-10.32) and DSF with (HR) $1.84(95 \% \mathrm{Cl}=3.27-7.36), 4.63(95 \% \mathrm{Cl}=3.61-12.12)$, respectively. None of the participants succumbed secondary to treatment toxicities although grade 4 side effects were attained by $20 \%$ of cases.
\end{abstract}

Conclusion: The triple modality induction in resectable gastric cancer is feasible with promising outcomes. The baseline inflammatory prognosticators attained a notable statistical link to many clinical/pathological variables. Moreover, NLR and dNLR behaved as autonomous indicators of clinical consequences for patients with gastric cancer managed with triple preoperative modality.

Keywords: Inflammatory response; Biomarkers in gastric cancer

\section{Introduction}

An amplified emphasis delved into improving abysmal outcomes for gastric cancer patients using perioperative chemotherapy with or without radiation [1-4]. At least three trials supported the survival benefits from postoperative chemo-radiotherapy [5-8]. The INT0116 study instituted postoperative chemo-radiotherapy as the supreme adjuvant approach. Further to this, a minimum of three trials have compared surgery with perioperative chemotherapy [9-11]. In the Seminal MAGIC trial, surgery was compared to surgery and perioperative chemotherapy [9]. Forty two percent of patients randomized to chemotherapy were able to accomplish the scheduled postoperative adjuvant course. Correspondingly, the substantial contenders for this approach was the intolerability of the postoperative chemotherapy, in addition to the comparatively elevated local recuurence [9-11]. The modest prognosis attained with the aforementioned approaches instigated the exploration of intensified triple modality preoperative strategy that entailed induction chemotherapy for two cycles to be succeeded by chemo-radiation course then surgery [12-14]. Fortunately, the preoperative strategy allowed for a surveillance window to explore the tumor biology prior to embarking on a major resection [12-14].

Furthermore, the assorted prospects for gastric cancer patients have mandated that effective biomarkers be adopted to optimize forecasting of outcomes. In recent work, chronic inflammation was extensively incriminated in the induction and promotion of carcinogenesis
$[15,16]$. Malignant cells can modulate and optimize the performance of various leukocytes through $\mathrm{T}$ lymphocytes conditioning, this principle applies for neutrophils, monocytes and platelets alongside specified prostaglandins and chemokines [17,21]. Consequently, the priming of inflammatory cells can promote tumor evolution and the distant dissemination via the acceleration of inflammatory intermediaries and cytokines [22]. Lately, many forecasters driven from blood such as the neutrophil to lymphocyte ratio (NLR), derived neutrophil to lymphocyte ratio (dNLR), platelet to lymphocyte ratio (PLR) and lymphocyte to monocyte ratio (LMR) have been extensively explored as prognosticators in various cancers [23-27]. In reality, only 1 or 2 biomarkers have been explored in gastric cancer patients [11,17-21]. In addition, the heterogeneity in the threshold values for the previously tested indicators doubted their sensitivities and specificities in gastric

*Corresponding author: Dr. Hala Zaghloul, Department of Clinical Oncology Faculty of Medicine, Alexandria University, Egypt, Tel: 00201223926059; Fax 002034290746; E-mail: h_zagloul@yahoo.com

Received July 25, 2017; Accepted September 04, 2017; Published Septembe 08, 2017

Citation: Zaghloul H, Abbas A (2017) The Role of Baseline Inflammatory Response Biomarkers in Predicting the Prognosis in No Metastatic Gastric Cancer Patients Treated with Preoperative Chemoradiation. Cancer Sci Ther 9: 608-616. doi: 10.4172/1948-5956.1000481

Copyright: @ 2017 Zaghloul H, et al. This is an open-access article distributed under the terms of the Creative Commons Attribution License, which permits unrestricted use, distribution, and reproduction in any medium, provided the original author and source are credited. 
cancer patients. As a result, further assessment of these prognosticators became imperative. Concordantly, we focused on analyzing baseline NLR, d NLR, LMR and PLR as prognosticators that may predict the outcome for gastric cancer managed with triple modality strategy.

\section{Materials and Methods}

A retrospective review of gastric cancer patients treated at Surgical Oncology department National Cancer Institute Cairo University and Clinical Oncology department Alexanderia University, starting from January 2013 till December 2016 following Institutional Board approval (IRB). The participating patients provided their consent through signed forms. The patient's records were studied to segregate patients who received triple modality induction to collect the required clinical/ pathological characteristics. The calculation of tested pretreatment prognosticators NLR, dNLR = neutrophil count to (white cell countneutrophil count), PLR and LMR were carried out.

\section{Criteria for inclusion}

Non metastatic, localized, histologically verified T1, N1-2, and T23, N0-3 gastric or gastroesophageal adenocarcinoma. All participants should have tolerated two induction chemotherapy cycles that had fluorouracil $750 \mathrm{mg} / \mathrm{m} 2 /$ day on days 1 to 5 cisplatin $20 \mathrm{mg} / \mathrm{m} 2 /$ day on days1to5 and docetaxel $75 \mathrm{mg} / \mathrm{m} 2$.Four weeks later a dose of $45 \mathrm{~Gy}$ over five weeks was offered to patients with daily doses of $300 \mathrm{mg} / \mathrm{m} 2$ fluorouracil via continuous infusion in addition to weekly $20 \mathrm{mg} / \mathrm{m} 2$ docetaxel . R0 or R1 resections were exclusively added to the study. The $\mathrm{R} 0$ resection entailed radical elimination of clinical disease with the closest acceptable safety boundary of $2 \mathrm{~mm}$ width. While R1 resections involved microscopic residual carcinomas left in the tumor bed. The eligible participants were offered either subtotal or total gastrectomy based on the origins of their disease. The ideal lymph node dissection aimed at retrieving at least 15 regional lymph nodes. On the contrary, participants who harbored or developed distant dissemination in the triple modality phase and those who suffered macroscopic remaining carcinomas following surgery were excluded from the studied population.

\section{Statistical Consideration}

The interaction between the verified prognosticators and various clinical/pathological variables on was carried by the Mann-Whitney $\mathrm{U}$ test (between 2 groups) or Kruskal- Wallis test ( $\geq 3$ groups). The receiver operator curves (ROC) were deployed to discover the possible cutoffs of tested prognosticators. An area under the curve (AUC) < 0.5 demonstrates a non-informative test. The Kaplan-Meier alongside Cox regression and log rank approaches were applied for the survival analysis. The SPSS 16.0 package program was employed to carry out all statistical work.

\section{Results}

The inclusion requisites were fulfilled in 80 patients. The sample consisted of 24 female patients, registering at $30 \%$ of the pool, while 56 or $70 \%$ were males. The median age stood at 51 years. The baseline median values for the prognosticators were registered at 3.12 (NLR), 2.31 (dNLR), 3,97 (LMR) and 139 (PLR). The characteristics of all studied participants are illustrated in [Table1].

The implemented ROC had a baseline dNLR of 1.7 and NLR of 2.4, cutoff for forecasing DFS (AUC at $0.703 \& 0.683$ at $75.7 \%, 72 \%$ sensitivity and a $80 \%$ and $78 \%$ specificity), respectively (Figure 1). Moreover, it showed the ability of baseline PLR and LMR to forecast DFS (AUC stood at $0.695 \& 0.585$ at $71.2 \%, 68.2 \%$ sensitivity and $69.1 \%$,
$60.2 \%$ specificity), respectively. Moreover, the optimum LMR (5.1) and PLR (130) cutoffs were also established. Patients were split into two categories as per the threshold levels identified.

The verified prognosticators displayed a considerable link to initial disease burden as amplified baseline (PLR, LMR, dNLR and NLR) were principally encountered in poorly differentiated primaries alongside stage III disease which comprised larger tumors and extensive nodal diseases as illustrated in (Table 2). Precisely $85 \%$ of the participants, had complete resection. Another $15 \%$ or 12 patients had R1 resection. Both primary tumors and the draining lymph nodes attained total resolution of malignant cells as verified pathologically (path CR) in $22.5 \%$ of the patients i.e. 18 individuals. While $16.2 \%$ i.e. 13 patients developed relatively advantageous pathological partial response (path $\mathrm{PR}$ ) as less than $10 \%$ malignant cells were verified. Another 23 patients, who accounted for $28.7 \%$ of the sample, attained path PR with greater remaining cancer burden mounting up to $10-50 \%$ residual viable disease identified in postoperative pathology. The rate was different for 12 patients or $15 \%$ of the sample that presented with more than $50 \%$ residual disease. Overall, the pathologic response rate stood at $82.5 \%$. The 14 patients that remained experienced steady or advanced disease subsequent to neoadjuvant course. Subsequent to gastrectomy, primary carcinomas in 23 or $28.7 \%$ of cases was T3, while 16 patients or $20 \%$ were T2, 21 patients or $26.3 \%$ presented T1, and finally 20 patients or $25 \%$ presented T0. N0 cancer was observed in 27 patients or $33.8 \%$ of the pool, while $\mathrm{N} 1$ was observed in 41 patients or $51.2 \%$, and $\mathrm{N} 2$ was observed in $15 \%$ or 12 patients (Table 3 ). The median for the nodes stood at 19, with a range of 6 to 32. "The median for nodes with carcinoma stood at 4 while the median for cancer-free stood at 15 . It is worth stating that accentuated pathologic response was considerably related to lesser primary tumor and nodal burdens $(\mathrm{P}=0.003),(\mathrm{P}=0.002)$ alongside reduced expressions of NLR $(\mathrm{P}=0.001), \mathrm{d} \operatorname{NLR}(\mathrm{P}=0.0024)$, LMR $(\mathrm{P}=0.001)$ and $\mathrm{PLR}(\mathrm{P}=0.003)$, respectively (Table 4) (Figures 2 and 3)."

During the surveillance around $57.5 \%$ of the patients, or 46 people, failed treatment either locally or systemically. From this, 52.5\% or 42 succumbed secondary to their cancer. The estimated OS and DFS mounted to $47.5 \%$ and $42.5 \%$ with a median time interval that pointed to 25 and 20 months, in that order. The worst survivals were experienced by patients with extensive remaining cancer wider than $10 \%$ (Figure 4 ) alongside those who expressed enhanced NLR $(\geq 2.4)$ (Figures 5 and 6 ), dNLR ( $\geq 1.7)$ (Figures 7 and 8 ), PLR $(\geq 130)$ and LMR $(\geq 5.1)$ (Table 5). Furthermore, the amplified baseline NLR and dNLR alongside greater remaining tumor burden $>10 \%$ were substantially linked with dismal OS, with hazard ratio 2.04 (95\% confidence interval [CI], 2.41-8.24), 6.63 (95\% CI, 1.61-10.32) and 6.36 (95\% CI, 3.2711.34). Concordantly, worsened DFS was attributed to augmented baseline NLR, dNLR and $>10 \%$ residual tumor with hazard ratio 1.84 (95\% confidence interval [CI], 3.27-7.36), 4.63 (95\% CI, 3.61-12.12), and 7.35 (95\% CI, 2.57-13.54).

More information on toxicities that result from acute chemoradiotherapy were summarized in (Table 6). None of the participants succumbed secondary to treatment toxicities although grade 4 side effects were attained by $20 \%$ of them. Detailed delayed radiation toxicities were reported in (Table 7)."

\section{Postoperative complications}

Such issues presented in $42.5 \%$ of the patients, i.e. 34 individuals. The issues manifested within 30-day period after the surgery were listed in [Table8]. Anastomosis fistula, pneumonia, and hemorrhage after the 
Citation: Zaghloul H, Abbas A (2017) The Role of Baseline Inflammatory Response Biomarkers in Predicting the Prognosis in No Metastatic Gastric Cancer Patients Treated with Preoperative Chemoradiation. Cancer Sci Ther 9: 608-616. doi: 10.4172/1948-5956.1000481

\begin{tabular}{|c|c|c|}
\hline Characteristic & No. of patients & $\%$ \\
\hline \multicolumn{3}{|c|}{ Age, years } \\
\hline Median & 51 & - \\
\hline Range & $39-69$ & - \\
\hline \multicolumn{3}{|c|}{ Sex } \\
\hline Male & 56 & $70 \%$ \\
\hline Female & 24 & $30 \%$ \\
\hline \multicolumn{3}{|c|}{ Zubrod performance scale } \\
\hline 0 & 36 & $45 \%$ \\
\hline 1 & 38 & $47.50 \%$ \\
\hline 2 & 6 & $7.50 \%$ \\
\hline \multicolumn{3}{|c|}{ Primary site } \\
\hline Pylorus & 26 & $32.50 \%$ \\
\hline Cardia & 18 & $22.50 \%$ \\
\hline Fundus & 16 & $20 \%$ \\
\hline Body & 12 & $15 \%$ \\
\hline Gastroesophageal junction & 8 & $10 \%$ \\
\hline \multicolumn{3}{|c|}{ Histopathological type } \\
\hline Papillary & 4 & $5 \%$ \\
\hline Tubular & 17 & $21.20 \%$ \\
\hline Poorly differentiated & 40 & $50 \%$ \\
\hline Mucinous & 12 & $15 \%$ \\
\hline Signet ring & 7 & $8.80 \%$ \\
\hline \multicolumn{3}{|c|}{ Tumor grade } \\
\hline G1 & 2 & $2.50 \%$ \\
\hline G2 & 28 & $35 \%$ \\
\hline G3 & 50 & $62.50 \%$ \\
\hline \multicolumn{3}{|c|}{ T stage } \\
\hline T1 & 16 & $20 \%$ \\
\hline T2 & 20 & $25 \%$ \\
\hline T3 & 44 & $55 \%$ \\
\hline \multicolumn{3}{|c|}{ N stage } \\
\hline No & 18 & $22.50 \%$ \\
\hline $\mathrm{N} 1$ & 48 & $60 \%$ \\
\hline N2 & 14 & $17.50 \%$ \\
\hline \multicolumn{3}{|c|}{ Stage group } \\
\hline$\| \mathrm{A}$ & 32 & $40 \%$ \\
\hline IIB & 40 & $50 \%$ \\
\hline IIIA & 8 & $10 \%$ \\
\hline \multicolumn{3}{|c|}{ Inflammatory response biomarkers } \\
\hline \multicolumn{3}{|c|}{ NLR } \\
\hline Median & 3.12 & -- \\
\hline$<2.4$ & 27 & $33.80 \%$ \\
\hline$\geq 2.4$ & 53 & $66.20 \%$ \\
\hline \multicolumn{3}{|c|}{ dNLR } \\
\hline Median & 2.31 & -- \\
\hline$<1.7$ & 32 & $40 \%$ \\
\hline$\geq 1.7$ & 48 & $60 \%$ \\
\hline \multicolumn{3}{|c|}{ LMR } \\
\hline Median & 3.97 & -- \\
\hline$<5.1$ & 49 & $61.20 \%$ \\
\hline$\geq 5.1$ & 31 & $38.80 \%$ \\
\hline \multicolumn{3}{|c|}{ LMR } \\
\hline Median & 139 & -- \\
\hline$<130$ & 33 & $41.30 \%$ \\
\hline$\geq 130$ & 47 & $58.70 \%$ \\
\hline
\end{tabular}

Table 1: Patient Characteristics at baseline $(\mathrm{N}=80)$.

operation were the most common problems. Three patients, or $9.5 \%$ of the sample, were given interventions, while the median for the hospital stay stood at 12 days, within a five to 23 -day range.

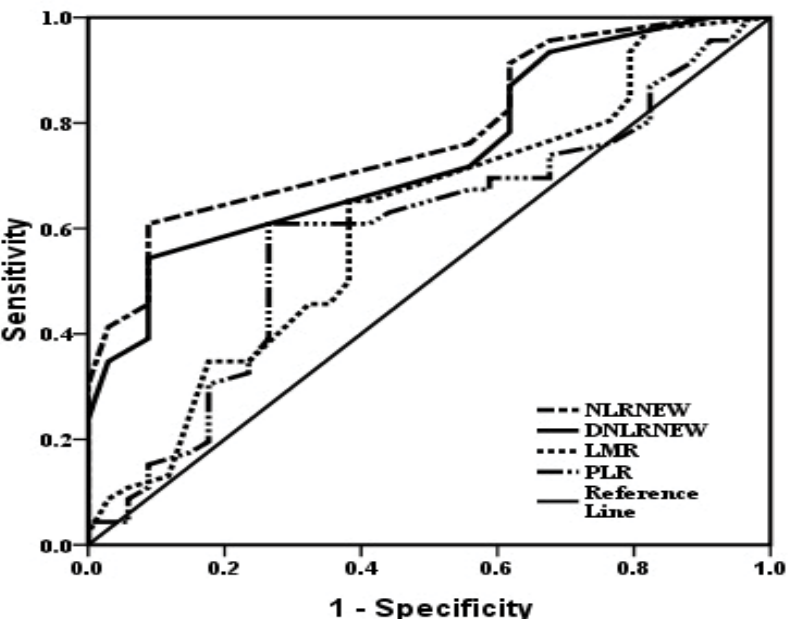

Figure 1: Optimal cut-off levels for NLR, dNLR, PLR and LMR were applied with ROC curves for cancer -specific survival.

\section{Discussion}

Several phase II trials were conducted to test the efficacy of preoperative chemo-radiation in improving abysmal outcomes previously attained in gastric cancer $[12,13,28]$. Eighty five percent of participants experienced $\mathrm{R} 0$ resection after a triple preoperative docetaxel-based modality. Furthermore, a CR path was noted in $22.5 \%$ or 18 of the participants. Ajani et al. concluded that applying the triple preoperative modality induced R0 resection and PCR in 70\% and $30 \%$ of the cases, correspondingly [12]. Concordantly, the RTOG 9904 trial concluded that PCR and R0 resection were accomplished by 26 and 77 $\%$ of similarly managed cases [28].

Recently, innovative researches have corroborated that cancer is influenced by inflammatory cells interaction in tumor microenvironment. An explicit interpretation of the contribution of individual cell in the inflammatory cascade induced by tumorigenesis will pave the pathway to attain precise targeted cancer therapy alongside the deceleration or even abolishment of carcinogenesis [29-32]. Consequently, our wok perspectives had revolved around shading lighter on the interaction of the specified prognosticators with conventional clinical/pathological elements, as well as their modulation of the studied patient outcomes. The ROC established baseline cut off values i.e. NLR (2. 4), dNLR (1.75), LMR (5. 1) and PLR (130) as forecasters of DFS in the studied participants. Deng et al conquered with our inference that augmented expressions of NLR, dNLR, LMR and PLR were linked to greater tumor burdens[33]."

It can be acknowledged that it is primary study to efficaciously establish the optimal cutoff values for baseline verified prognosticators in gastric cancers managed with triple preoperative modality. The worst survivals were experienced by patients with extensive remaining cancer $>10 \%$ alongside those who expressed enhanced NLR $(\geq 2.4)$, $\operatorname{dNLR}(\geq 1.7))$, PLR $(\geq 130)$ and LMR $(\geq 5.1)$.Concordantly, Deng et al ensued a substantial link of dNLR, NLR to survival consequences[33].

The outcomes emphasized in our work are sustained by the innovative body of evidence elaborating the chain of pathways stimulated by inflammatory cells in carcinogenesis [34-39].For instance enhanced neutrophils produce angiogenesis promoting factors, such as vascular endothelial growth factor (VEGF) which enhances neoplasm 
Citation: Zaghloul H, Abbas A (2017) The Role of Baseline Inflammatory Response Biomarkers in Predicting the Prognosis in No Metastatic Gastric Cancer Patients Treated with Preoperative Chemoradiation. Cancer Sci Ther 9: 608-616. doi: 10.4172/1948-5956.1000481

\begin{tabular}{|c|c|c|c|c|c|c|c|c|c|}
\hline \multirow[t]{2}{*}{ Characteristic } & \multirow[t]{2}{*}{ No. of patients } & \multirow[t]{2}{*}{$\%$} & \multirow{2}{*}{$\begin{array}{c}\text { Baseline NLR } \\
\text { P value }\end{array}$} & \multicolumn{2}{|c|}{ Baseline dNLR } & \multicolumn{2}{|c|}{ Baseline LMR } & \multicolumn{2}{|c|}{ Baseline PLR } \\
\hline & & & & Median & $P$ value & Median & $P$ value & Median & $P$ value \\
\hline \multicolumn{10}{|c|}{ Age, years } \\
\hline$<50$ & 38 & $47.50 \%$ & 0.646 & 1.9 & 0.478 & 3.6 & 0.347 & 125 & \multirow[t]{2}{*}{0.673} \\
\hline$\geq 50$ & 42 & $52.50 \%$ & - & 1.8 & - & 3.9 & - & 128 & \\
\hline \multicolumn{10}{|c|}{ Sex } \\
\hline Male & 56 & $70 \%$ & 0.684 & 1.9 & 0.473 & 3.1 & 0.521 & 122 & \multirow[t]{2}{*}{$0.0164^{*}$} \\
\hline Female & 24 & $30 \%$ & - & 1.7 & - & 3.4 & - & 125 & \\
\hline \multicolumn{10}{|c|}{ Primary site } \\
\hline Pylorus & 26 & $32.50 \%$ & - & 1.7 & - & 2.7 & - & 121 & \multirow[t]{5}{*}{0.348} \\
\hline Cardia & 18 & $22.50 \%$ & 0.783 & 1.9 & 0.623 & 3.6 & 0.546 & 123 & \\
\hline Fundus & 16 & $20 \%$ & - & 2.1 & - & 3.8 & - & 118 & \\
\hline Body & 12 & $15 \%$ & - & 1.6 & - & 4.6 & - & 125 & \\
\hline Gastroesophageal junction & 8 & $10 \%$ & - & 2.3 & - & 4.3 & - & 122 & \\
\hline \multicolumn{10}{|c|}{ Histopathological type } \\
\hline Papillary & 4 & $5 \%$ & - & 1.6 & - & 3.2 & - & 126 & \multirow[t]{5}{*}{$0.0236^{*}$} \\
\hline Tubular & 17 & $21.20 \%$ & $0.0412^{*}$ & 1.9 & $0.0342^{*}$ & 3.6 & $0.0321^{*}$ & 128 & \\
\hline Poorly differentiated & 40 & $50 \%$ & - & 3.1 & - & 5.1 & - & 139 & \\
\hline Mucinous & 12 & $15 \%$ & - & 3.7 & - & 4.9 & - & 141 & \\
\hline Signet ring & 7 & $8.80 \%$ & - & 3.8 & - & 5.2 & - & 145 & \\
\hline \multicolumn{10}{|c|}{ Tumor grade } \\
\hline G1 & 2 & $2.50 \%$ & $0.0112^{*}$ & 1.6 & $0.0214^{*}$ & 2.5 & $0.0345^{\star}$ & 110 & \multirow[t]{3}{*}{$0.0215^{*}$} \\
\hline G2 & 28 & $35 \%$ & - & 1.9 & - & 3.1 & - & 121 & \\
\hline G3 & 50 & $62.50 \%$ & - & 4.2 & - & 5.3 & - & 156 & \\
\hline \multicolumn{10}{|c|}{ T stage } \\
\hline T1 & 16 & $20 \%$ & - & 1.6 & - & 3.1 & - & 123 & \multirow[t]{3}{*}{$0.0126^{*}$} \\
\hline T2 & 20 & $25 \%$ & $0.0216^{*}$ & 2.1 & $0.0315^{*}$ & 3.4 & $0.0316^{*}$ & 137 & \\
\hline T3 & 44 & $55 \%$ & - & 4.1 & - & 5.3 & - & 141 & \\
\hline \multicolumn{10}{|c|}{$\mathrm{N}$ stage } \\
\hline No & 18 & $22.50 \%$ & - & 1.5 & - & 2.9 & - & 122 & \multirow[t]{3}{*}{$0.0112^{*}$} \\
\hline N1 & 48 & $60 \%$ & $0.0234^{*}$ & 2.3 & $0.0156^{*}$ & 3.9 & $0.0134^{*}$ & 138 & \\
\hline N2 & 14 & $17.50 \%$ & - & 4.3 & - & 5.6 & - & 149 & \\
\hline \multicolumn{10}{|c|}{ Stage group } \\
\hline IIA & 32 & $40 \%$ & - & 1.9 & - & 3.1 & - & 134 & \multirow[t]{3}{*}{$0.011^{*}$} \\
\hline IIB & 40 & $50 \%$ & $0.0245^{*}$ & 2.8 & $0.0321^{*}$ & 4.7 & $0.034^{\star}$ & 142 & \\
\hline IIIA & 8 & $10 \%$ & - & 5.3 & - & 5.9 & - & 150 & \\
\hline
\end{tabular}

Table 2: Association between inflammatory biomarkers and different clinicopathological parameters.

\begin{tabular}{|c|c|c|c|c|c|}
\hline \multirow[t]{2}{*}{ Variables } & \multicolumn{2}{|c|}{ Baseline } & \multicolumn{2}{|c|}{ After induction chemoradiation } & \multirow{2}{*}{$\begin{array}{l}\text { Wilcoxon signed rank test Asymp. sig (2 } \\
\text { tailed) }\end{array}$} \\
\hline & No of pts & $\%$ & No of pts & $\%$ & \\
\hline \multicolumn{6}{|c|}{ T stage } \\
\hline T0 & 0 & - & 20 & $25 \%$ & \multirow{4}{*}{$0.002^{*}$} \\
\hline T1 & 0 & - & 21 & $26.30 \%$ & \\
\hline $\mathrm{T} 2$ & 20 & $25 \%$ & 16 & $20 \%$ & \\
\hline T3 & 60 & $75 \%$ & 23 & $28.70 \%$ & \\
\hline \multicolumn{6}{|c|}{ N stage } \\
\hline No & 18 & $22.5 \%$ & 27 & $33.80 \%$ & \multirow[t]{3}{*}{$0.034^{*}$} \\
\hline $\mathrm{N} 1$ & 49 & $61.2 \%$ & 41 & $51.20 \%$ & \\
\hline $\mathrm{N} 2$ & 13 & $16.3 \%$ & 12 & $15 \%$ & \\
\hline
\end{tabular}

Table 3: Patient Response to Chemoradiotherapy $(\mathrm{N}=80)$.

evolution [34,35].Correspondingly, accentuated expression of VEGF was appreciated in gastric cancer specimens compared to normal gastric tissues and it was linked to augmented stimulation of VEGF receptor 2 that induced proliferation gastric cancer cells [36,37]. Surprisingly, studies clarified that neutrophils suppress $\mathrm{T}$ cell function through release of cytotoxic chemokines (nitric oxide and arginase) resulting in abolishment of lymphocyte mediated tumoricidal pathways. Consequently, augmented NLR behaved as a self-regulating indicator for cancer specific survival for certain cancers [38,39]."

Our study delved into the interaction of innovative prognosticators
(NLR, dNLR, PLR, LMR) with different clinical/pathological indicators and scrutinized on their prospective in forecasting gastric cancer patients' outcome, specifically those that have been given preoperative triple modality. Additional, the studied participants received consistent neoadjuvant treatment which precluded any confounding influence on prognosis that might be induced by applying dissimilar treatment modalities.

However, the conducted work suffered certain restrictions caused by its retrospective strategy alongside the limited number of participants eligible for inclusion. Additionally, we did not explore 
Citation: Zaghloul H, Abbas A (2017) The Role of Baseline Inflammatory Response Biomarkers in Predicting the Prognosis in No Metastatic Gastric Cancer Patients Treated with Preoperative Chemoradiation. Cancer Sci Ther 9: 608-616. doi: 10.4172/1948-5956.1000481

\begin{tabular}{|c|c|c|c|c|}
\hline Characteristic & Patients & No & $\%$ CR & $\mathbf{P}$ \\
\hline \multicolumn{5}{|c|}{ Age, years } \\
\hline Median & 51 & - & - & - \\
\hline Range & $39-69$ & - & - & - \\
\hline \multicolumn{5}{|c|}{ Sex } \\
\hline Male & 56 & 12 & $21.40 \%$ & \multirow[t]{2}{*}{0.74} \\
\hline Female & 24 & 6 & $25 \%$ & \\
\hline \multicolumn{5}{|c|}{ Primary site } \\
\hline Pylorus & 26 & 6 & $23.10 \%$ & \multirow[t]{5}{*}{0.78} \\
\hline Cardia & 18 & 4 & $22.20 \%$ & \\
\hline Fundus & 16 & 3 & $18.70 \%$ & \\
\hline Body & 12 & 3 & $25 \%$ & \\
\hline Gastroesophageal Junction & 8 & 2 & $25 \%$ & \\
\hline \multicolumn{5}{|c|}{ Histopathological type } \\
\hline Papillary & 4 & 2 & $50 \%$ & \multirow[t]{5}{*}{$0.04^{*}$} \\
\hline Tubular & 17 & 6 & $35.30 \%$ & \\
\hline Poorly differentiated & 40 & 10 & $25 \%$ & \\
\hline Mucinous & 12 & 0 & $0 \%$ & \\
\hline Signet Ring & 7 & 0 & $0 \%$ & \\
\hline \multicolumn{5}{|c|}{ Tumor grade } \\
\hline G1 & 2 & 2 & $100 \%$ & \multirow[t]{3}{*}{$0.03^{*}$} \\
\hline G2 & 28 & 6 & $21.40 \%$ & \\
\hline G3 & 50 & 10 & $20 \%$ & \\
\hline \multicolumn{5}{|c|}{ T stage } \\
\hline T1 & 5 & 5 & $100 \%$ & \multirow[t]{3}{*}{$0.003^{*}$} \\
\hline T2 & 20 & 12 & $60 \%$ & \\
\hline T3 & 55 & 1 & $0.02 \%$ & \\
\hline \multicolumn{5}{|c|}{ N stage } \\
\hline No & 18 & 12 & $67 \%$ & \multirow[t]{3}{*}{$0.002^{*}$} \\
\hline N1 & 49 & 6 & $33 \%$ & \\
\hline N2 & 13 & 0 & - & \\
\hline \multicolumn{5}{|c|}{ Stage group } \\
\hline IIA & 32 & 14 & $78 \%$ & \multirow[t]{3}{*}{$0.003^{*}$} \\
\hline IIB & 40 & 4 & $22 \%$ & \\
\hline IIIA & 8 & 0 & - & \\
\hline \multicolumn{5}{|c|}{ Inflammatory response biomarkers } \\
\hline \multicolumn{5}{|c|}{ NLR } \\
\hline Median & 3.12 & - & - & \multirow[t]{3}{*}{$0.001^{*}$} \\
\hline$<2.4$ & 27 & 12 & $67 \%$ & \\
\hline$\geq 2.4$ & 53 & 6 & $33 \%$ & \\
\hline \multicolumn{5}{|c|}{ dNLR } \\
\hline Median & 2.31 & - & - & \multirow[t]{3}{*}{$0.0024^{*}$} \\
\hline$<1.7$ & 32 & 14 & $78 \%$ & \\
\hline$\geq 1.7$ & 48 & 4 & $22 \%$ & \\
\hline \multicolumn{5}{|c|}{ LMR } \\
\hline Median & 3.97 & - & - & $0.001^{*}$ \\
\hline$<5.1$ & 49 & 13 & $72 \%$ & \\
\hline$\geq 5.1$ & 31 & 5 & $28 \%$ & \\
\hline & PLR & & & \\
\hline Median & 139 & - & - & $0.003^{*}$ \\
\hline$<130$ & 33 & 11 & $61 \%$ & \\
\hline$\geq 130$ & 47 & 7 & $39 \%$ & \\
\hline
\end{tabular}

Table 4: Association between pathological complete response and different clinicopathological parameters.

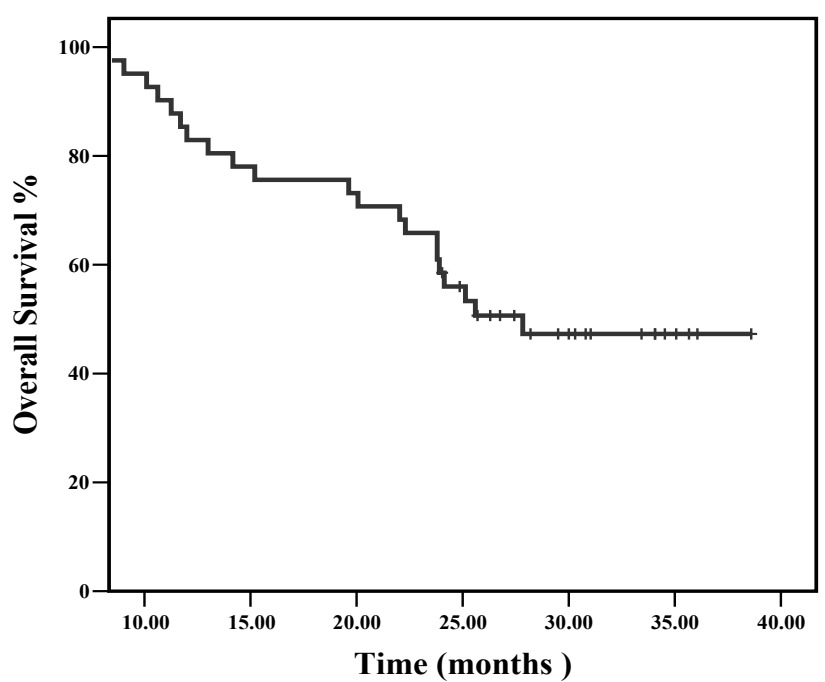

Figure 2: Overall survival in months.

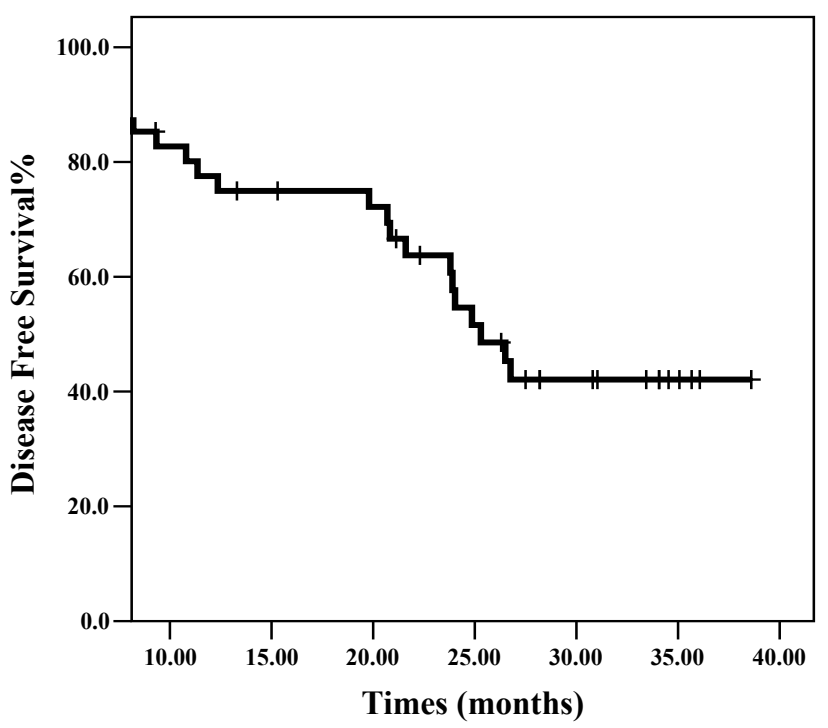

Figure 3: Disease free survival in months.

the modulation of the tested prognosticators can exert on tumor infiltrating lymphocytes.

\section{Conclusion}

The triple modality induction in resectable gastric cancer is feasible with promising outcomes. The baseline inflammatory prognosticators attained a notable statistical link to many clinical/pathological variables. Moreover, NLR and dNLR were revealed as independent prognosticators gastric cancer managed with triple preoperative modality. Finally, future work is required to validate their prognostic potential.

\section{Conflict of Interest}

The authors confirm that no form of financial support, including funding, was received for the study. They further confirm that the study at hand presented no struggle of interest. 


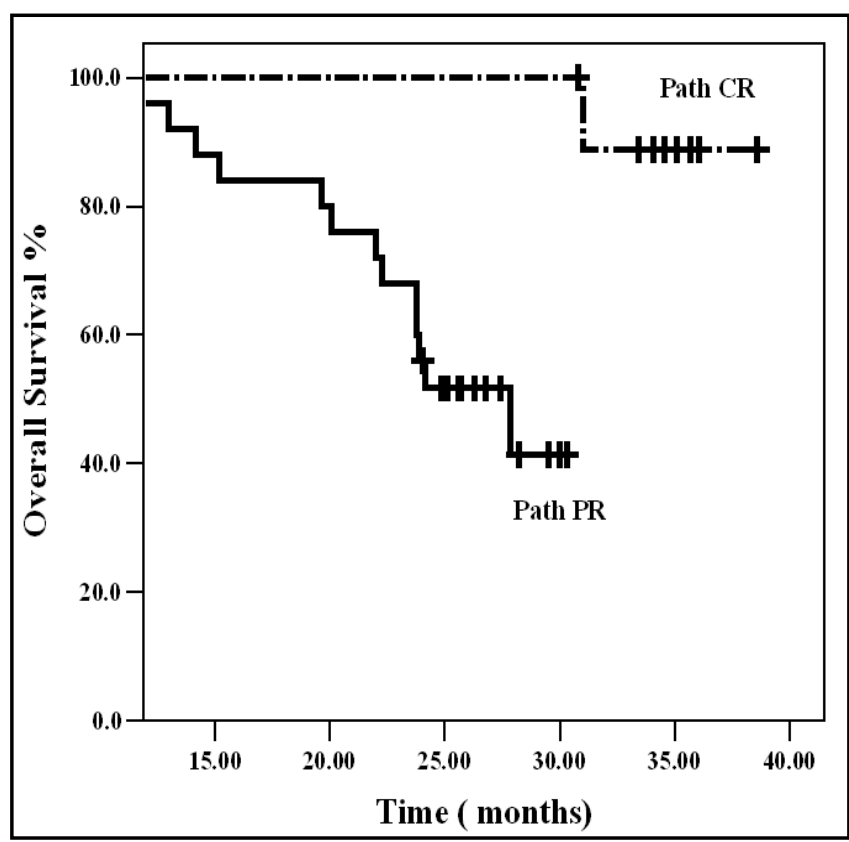

Figure 4: Overall survival by pathological response.

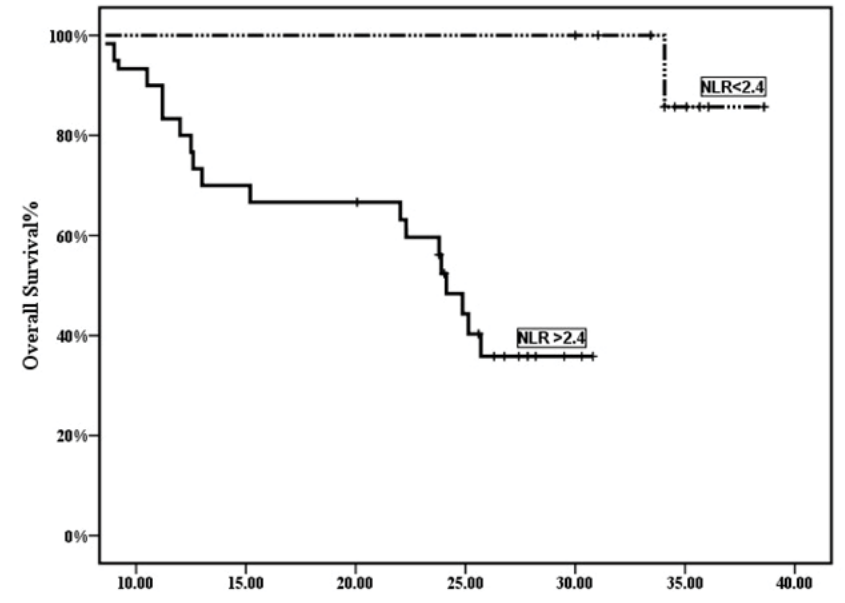

Figure 5: Overall survival in months.

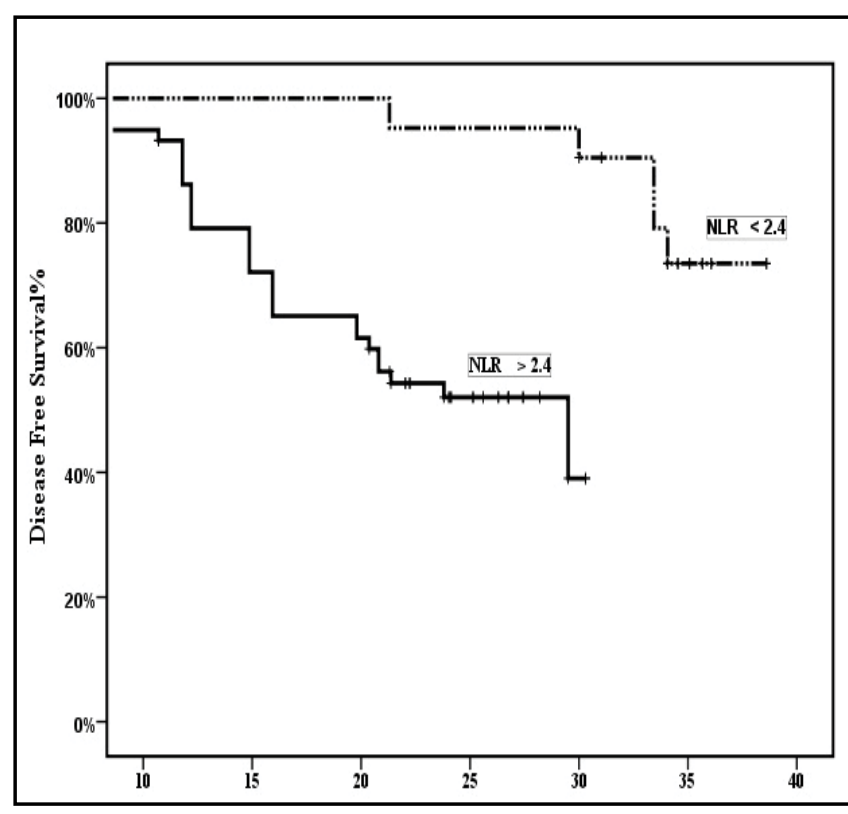

Figure 6: Disease free survival in months.

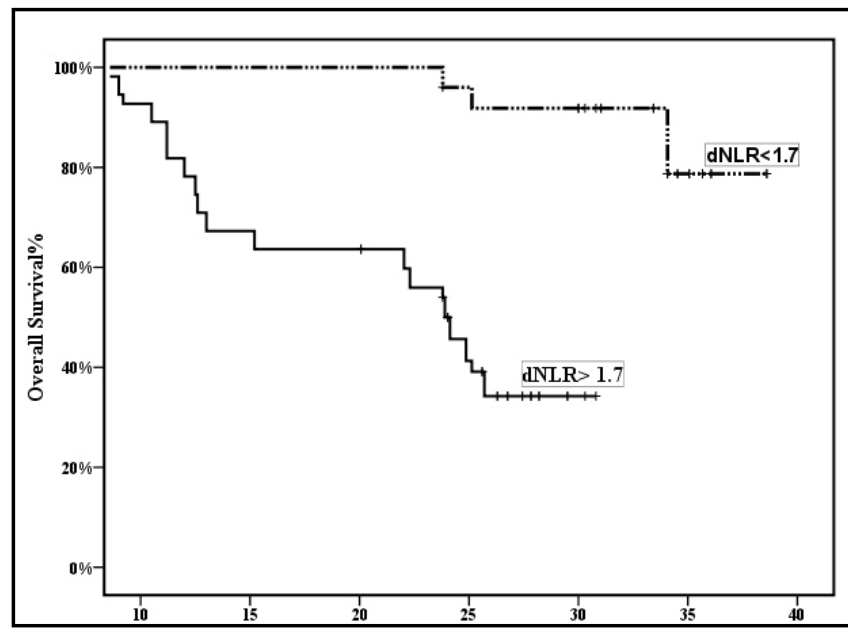

Figure 7: Overall survival in months.

\begin{tabular}{|c|c|c|c|c|c|c|}
\hline \multirow[t]{2}{*}{ Characteristic } & \multirow[t]{2}{*}{ No. of Patients and \% } & \multicolumn{2}{|c|}{ Overall survival of patients alive 38} & \multicolumn{3}{|c|}{ Disease free survival of patients 34 free of disease } \\
\hline & & no (\%) & $P$ value & no (\%) & & \\
\hline \multicolumn{7}{|c|}{ Age, years } \\
\hline$<50$ & $38(47.5 \%)$ & $16(42.1 \%)$ & \multirow[t]{2}{*}{$0.001^{*}$} & \multicolumn{2}{|c|}{$14(41.2 \%)$} & \multirow[t]{2}{*}{$0.002^{*}$} \\
\hline$\geq 50$ & $42(52.5 \%)$ & $22(57.9 \%)$ & & \multicolumn{2}{|c|}{$20(58.8 \%)$} & \\
\hline \multicolumn{7}{|c|}{ Sex } \\
\hline Male & $56(70 \%)$ & $18(47.4 \%)$ & \multirow[t]{2}{*}{0.534} & & & \multirow[t]{2}{*}{0.612} \\
\hline Female & $24(30 \%)$ & $20(52.6 \%)$ & & & $.1 \%)$ & \\
\hline \multicolumn{7}{|c|}{ Primary site } \\
\hline Pylorus & $26(32.5 \%)$ & $3(8 \%)$ & \multirow[t]{5}{*}{0.645} & & & \multirow[t]{5}{*}{0.731} \\
\hline Cardia & $18(22.5 \%)$ & $15(39.5 \%)$ & & \multicolumn{2}{|c|}{$15(44 \%)$} & \\
\hline Fundus & $16(20 \%)$ & $9(23.6 \%)$ & & \multicolumn{2}{|c|}{$8(23.5 \%)$} & \\
\hline Body & $12(15 \%)$ & $4(10.5 \%)$ & & \multicolumn{2}{|c|}{$2(6 \%)$} & \\
\hline oesophageal Junction & $8(10 \%)$ & $7(18.4 \%)$ & & \multicolumn{2}{|c|}{$7(20.5 \%)$} & \\
\hline
\end{tabular}


Citation: Zaghloul H, Abbas A (2017) The Role of Baseline Inflammatory Response Biomarkers in Predicting the Prognosis in No Metastatic Gastric Cancer Patients Treated with Preoperative Chemoradiation. Cancer Sci Ther 9: 608-616. doi: 10.4172/1948-5956.1000481

\begin{tabular}{|c|c|c|c|c|c|}
\hline \multicolumn{6}{|c|}{ Histopathological type at diagnosis } \\
\hline Papillary & $4(5 \%)$ & $4(10.5 \%)$ & \multirow[t]{5}{*}{0.145} & $4(12 \%)$ & \multirow[t]{5}{*}{0.632} \\
\hline Tubular & $17(21.2 \%)$ & $16(42.1 \%)$ & & $16(47 \%)$ & \\
\hline Poorly differentiated & $40(50 \%)$ & $15(39.4 \%)$ & & $13(38 \%)$ & \\
\hline Mucinous & $12(15 \%)$ & $3(8 \%)$ & & $1(3 \%)$ & \\
\hline Signet Ring & $7(8.8 \%)$ & 0 & & 0 & \\
\hline \multicolumn{6}{|c|}{ Tumor Grade at diagnosis } \\
\hline G1 & $2(2.5 \%)$ & $2(5 \%)$ & \multirow[t]{3}{*}{$0.001^{*}$} & $2(6 \%)$ & \multirow[t]{3}{*}{$0.011^{*}$} \\
\hline G2 & $28(35 \%)$ & $28(74 \%)$ & & $28(82 \%)$ & \\
\hline G3 & $50(62.5 \%)$ & $8(21 \%)$ & & & \\
\hline \multicolumn{6}{|c|}{ T stage at diagnosis } \\
\hline T1 & $16(20 \%)$ & $16(42 \%)$ & \multirow[t]{3}{*}{$0.013^{*}$} & $16(47 \%)$ & \multirow[t]{3}{*}{$0.002^{*}$} \\
\hline $\mathrm{T} 2$ & $20(25 \%)$ & $19(50 \%)$ & & $17(50 \%)$ & \\
\hline T3 & $44(55 \%)$ & $3(8 \%)$ & & $1(3 \%)$ & \\
\hline \multicolumn{6}{|c|}{$\mathrm{N}$ stage at diagnosis } \\
\hline No & $18(22.5 \%)$ & $18(47.4 \%)$ & \multirow[t]{3}{*}{$0.002^{*}$} & $18(53 \%)$ & \multirow[t]{3}{*}{$0.031^{*}$} \\
\hline N1 & $48(60 \%)$ & $16(42.1 \%)$ & & $14(41 \%)$ & \\
\hline N2 & $14(17.5 \%)$ & $4(10.5 \%)$ & & $2(6 \%)$ & \\
\hline \multicolumn{6}{|c|}{ Stage group at diagnosis } \\
\hline IIA & 32 & $29(76.3 \%)$ & \multirow[t]{3}{*}{$0.001^{*}$} & $26(76 \%)$ & \multirow[t]{3}{*}{$0.004^{*}$} \\
\hline IIB & 40 & $9(23.7 \%)$ & & $8(24 \%)$ & \\
\hline IIIA & 8 & 0 & & 0 & \\
\hline \multicolumn{6}{|c|}{ Pathological response } \\
\hline Complete response at primary site and $\mathrm{LN}$ & $18(22.5 \%)$ & $18(47.4 \%)$ & \multirow[t]{5}{*}{$0.001^{*}$} & $18(53 \%)$ & \multirow[t]{5}{*}{$0.003^{*}$} \\
\hline Partial response with $<10 \%$ residual tumor & $13(16.2 \%)$ & $12(31.6 \%)$ & & $12(35 \%)$ & \\
\hline $\begin{array}{c}\text { Partial response with } 10 \% \text { to } 50 \% \text { residual } \\
\text { tumor }\end{array}$ & $23(28.8 \%)$ & $8(21 \%)$ & & $4(12 \%)$ & \\
\hline Partial response with $>50 \%$ residual tumor & $12(15 \%)$ & 0 & & 0 & \\
\hline Stable or progressive disease & $14(17.5 \%)$ & 0 & & 0 & \\
\hline \multicolumn{6}{|c|}{ Type of resection } \\
\hline Ro & $68(85 \%)$ & $30(79 \%)$ & \multirow[t]{2}{*}{$0.004^{*}$} & $28(74 \%)$ & \multirow[t]{2}{*}{$0.002^{*}$} \\
\hline R1 & $12(15 \%)$ & $8(21 \%)$ & & $6(16 \%)$ & \\
\hline \multicolumn{6}{|c|}{ Inflammatory Response biomarkers at diagnosis } \\
\hline & & NLR & & & \\
\hline Median & 3.12 & & $0.013^{*}$ & & $0.032^{*}$ \\
\hline$<2.4$ & $27(33.8 \%)$ & $24(63.2 \%)$ & & $22(65 \%)$ & \\
\hline$\geq 2.4$ & $53(66.2 \%)$ & $14(36.8 \%)$ & & $12(35 \%)$ & \\
\hline & & dNLR & & & \\
\hline Median & 2.31 & - & $0.016^{*}$ & - & $0.011^{*}$ \\
\hline$<1.7$ & $32(40 \%)$ & $25(65.8 \%)$ & & $23(68 \%)$ & \\
\hline$\geq 1.7$ & $48(60 \%)$ & $13(34.2 \%)$ & & $11(32 \%)$ & \\
\hline & & LMR & & & \\
\hline Median & 3.97 & & $0.014^{*}$ & - & $0.021^{*}$ \\
\hline$<5.1$ & $49(61.2 \%)$ & $28(73.7 \%)$ & & $26(76.5 \%)$ & \\
\hline$\geq 5.1$ & $31(38.8 \%)$ & $10(26.3 \%)$ & & $8(23.5 \%)$ & \\
\hline & & PLR & & & \\
\hline Median & 139 & - & $0.027^{*}$ & - & $0.001^{*}$ \\
\hline$<130$ & $33(41.3 \%)$ & $26(68.4 \%)$ & & $25(73.5 \%)$ & \\
\hline$\geq 130$ & $47(58.7 \%)$ & $12(31.6 \%)$ & & $9(26.5 \%)$ & \\
\hline
\end{tabular}

Table 5: Association between different clinicopathological parameters and clinical prognosis.

\section{References}

1. Jemal A, Bray F, Center MM, Ferly J, Ward E, et al. (2011) Global cancer statistics. CA Cancer J Clin 61: 69-90.

2. Siegel R, Ward E, Brawley O, Jemal A (2011) Cancer statistics, 2011: The impact of eliminating socioeconomic and racial disparities on premature cancer deaths. CA Cancer J Clin 61: 212-236.

3. Agboola O (1994) Adjuvant treatment in gastric cancer. Cancer Treat Rev 20: 217-240.

4. Gunderson LL, Sosin H (1982) Adenocarcinoma of the stomach: Areas of failure in a re-operation series (second or symptomatic look) clinicopathologic correlation and implications for adjuvant therapy. Int J Radiat Oncol Biol Phys 8: 1-11.

5. Macdonald JS, Smalley SR, Benedetti J, Hundhal SA, Estes NC, et al (2001) Chemoradiotherapy after surgery compared with surgery alone for adenocarcinoma of the stomach or gastroesophageal junction. N Engl J Med 345: 725-730.

6. Dent DM, Werner ID, Novis B, Cheverton P, Brice P (1979) Prospective randomized trial of combined oncological therapy for gastric carcinoma. Cancer 44: 385-391. 
Citation: Zaghloul H, Abbas A (2017) The Role of Baseline Inflammatory Response Biomarkers in Predicting the Prognosis in No Metastatic Gastric Cancer Patients Treated with Preoperative Chemoradiation. Cancer Sci Ther 9: 608-616. doi: 10.4172/1948-5956.1000481

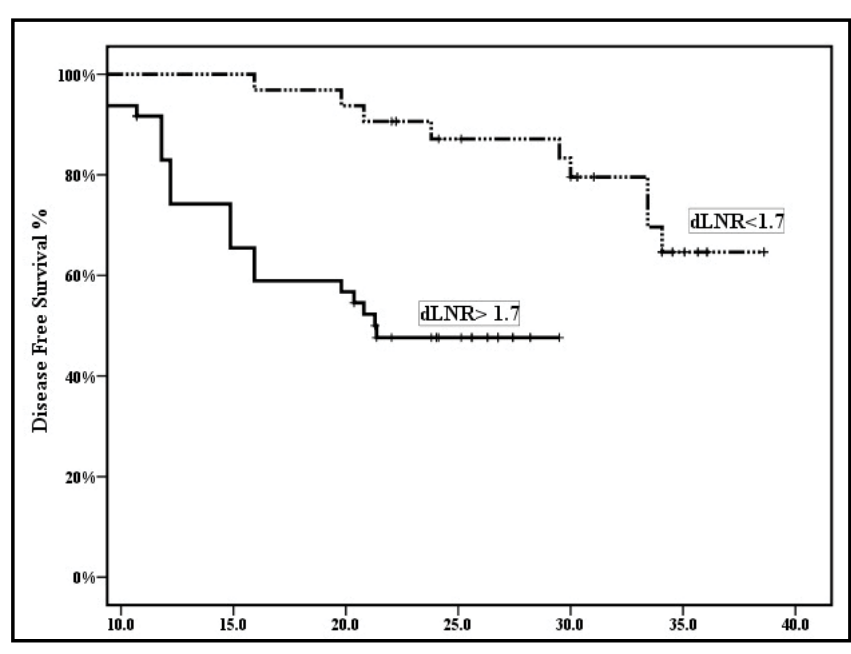

Figure 8: Disease free survival in months.

\begin{tabular}{|c|c|c|c|c|}
\hline \multirow{2}{*}{ Toxicity Blood/bone marrow } \\
\cline { 2 - 4 } & 1 & 2 & 3 & 4 \\
\hline Hemoglobindecreased & 36 & 24 & 4 & 2 \\
\hline Neutropenia & 16 & 6 & 16 & 2 \\
\hline Platelet count decreased & 14 & 6 & 8 & 4 \\
\hline Anorexia & - & 26 & 8 & 3 \\
\hline Dehydration & - & 10 & 18 & 0 \\
\hline Esophagitis & - & 8 & 6 & 0 \\
\hline Gastritis & - & 14 & 2 & 0 \\
\hline Nausea & - & 46 & 14 & 0 \\
\hline Stomatitis & - & 8 & 12 & 0 \\
\hline Vomiting & - & 32 & 8 & 4 \\
\hline Febrile Neutropenia & - & 6 & 4 & 1 \\
\hline \multicolumn{7}{|c|}{ Neurology } \\
\hline Peripheral sensory neuropathy & 12 & 8 & 4 & 0 \\
\hline Fatigue & 20 & 30 & 10 & 0 \\
\hline Weight decreased & 12 & 12 & 14 & 0 \\
\hline
\end{tabular}

Table 6: Selected chemotherapy and acute radiotherapy toxicities $(n=80)$.

\begin{tabular}{|c|c|c|c|c|}
\hline \multirow{2}{*}{ Toxicity } & \multicolumn{5}{|c|}{ Grade } \\
\cline { 2 - 5 } & $\mathbf{1}$ & $\mathbf{2}$ & $\mathbf{3}$ & $\mathbf{4}$ \\
\hline \multicolumn{5}{|c|}{ Gastrointestinal } \\
\hline Esophagitis & 1 & 2 & 3 & 0 \\
\hline Gastritis & 1 & 3 & 1 & 0 \\
\hline Skin & 2 & 0 & 0 & 0 \\
\hline
\end{tabular}

Table 7: Late radiation toxicities $(n=80)$.

7. Moertel CG, Childs DS, O'Fallon JR, Holbrook MA, Schutt AJ, et al. (1984) Combined 5-fluorouracil and radiation therapy as a surgical adjuvant for poor prognosis gastric carcinoma. J Clin Oncol 2: 1249-1254.

8. Schwartz GK, Winter K, Minsky BD, Crane C, Thomson PJ, et al. (2009) Randomized phase II trial evaluating two paclitaxel and cisplatin-containing chemoradiation regimens as adjuvant therapy in resected gastric cancer (RTOG-0114). J Clin Oncol 27: 1956-1962.

9. Songun I, Keizer HJ, Hermans J, Klementschitsch P, De Vries JE, et al. (1999) Chemotherapy for operable gastric cancer: Results of the Dutch randomised FAMTX trial. The Dutch Gastric Cancer Group (DGCG). Eur J Cancer 35: 558562

10. Boige V, Pignon J, Saint-Aubert B, Lasser P, Conroy T (2007) Final results

\begin{tabular}{|c|c|c|}
\hline Complications & No. of Patients (80) & \% \\
\hline No. of patients with complications & 34 & 42.5 \\
\hline Wound infection & 6 & 7.5 \\
\hline Anastomosis fistula & 4 & 5 \\
\hline Intra-abdominal abscess & 6 & 7.5 \\
\hline Postoperative haemorrhage & 5 & 6.3 \\
\hline \multicolumn{2}{|c|}{ General complications } & 5 \\
\hline Catheter sepsis & 4 & 5 \\
\hline Thromboembolism & 4 & 6.2 \\
\hline
\end{tabular}

Table 8: Surgical morbidity and mortality.

of a randomized trial comparing preoperative 5-fluorouracil/cisplatin to surgery alone in adenocarcinoma of stomach and lower esophagus (ASLE): FNLCC ACCORD07-FFCD 9703 trial (abstract). J Clin Oncol 25: 4510.

11. Ajani JA, Mansfield PF, Lynch PM, Pisters PW, Feig B, et al. (1999) Enhanced staging and all chemotherapy preoperatively in patients with potentially resectable gastric carcinoma. J Clin Oncol 17: 2403-2411.

12. Ajani JA, Mansfield P, Janjan N, Morris J, Pisters PW, et al. (2004) Multiinstitutional trial of preoperative chemoradiotherapy in patients with potentially resectable gastric carcinoma. J Clin Oncol 22: 2774-2780.

13. Ajani JA, Mansfield PF, Crane CH, WuTT, Lunagomez S, et al. (2005) Paclitaxel-based chemoradiotherapy in localized gastric carcinoma: degree of pathologic response and not clinical parameters dictated patient outcome. $J$ Clin Oncol 23: 1237-1244.

14. Ajani JA, Fodor MB, Tjulandin SA, Moiseyenko VM, Chao Y, et al. (2005) Phase II multi institutional randomized trial of docetaxel plus cisplatin with or without fluorouracil in patients with untreated, advanced gastric, or gastroesophageal adenocarcinoma. J Clin Oncol 23: 5660-5667.

15. Mantovani A, Allavena P, Sica A, Balkwill F (2008) Cancer-related inflammation. Nature 454: 436-444.

16. Lee K, Hwang $\mathrm{H}$, Nam KT (2014) Immune response and the tumor microenvironment: How they communicate to regulate gastric cancer. Gut Live 8: 131-139.

17. Mantovani A, Allavena P, Sica A, Balkwill F (2008) Cancer-related inflammation. Nature 454: 436-444

18. Stoppacciaro A, Melani C, Parenza M, Mastracchio A, Bassi C, et al (1993) Regression of an established tumor genetically modified to release granulocytecolony-stimulating factor requires granulocyte-T cell cooperation and T cell-produced interferon gamma. J Exp Med 178: 151-161.

19. Bellocq A, Antoine M, Flahault A, Philippe C, Crestani B, et al. (1998) Neutrophi alveolitis in bronchioloalveolar carcinoma: Induction by tumor-derived interleukin-8 and relation to clinical outcome. Am J Pathol 152: 83-92.

20. De Larco JE, Wuertz BR, Furcht LT (2004) The potential role of neutrophils in promoting the metastatic phenotype of tumors releasing interleukin-8. Clin Cancer Res 10: 4895-4900.

21. Ghasemzadeh M, Hosseini E (2013) Platelet-leukocyte crosstalk: Linking proinflammatory responses to procoagulant state. Thromb Res 131: 191-197.

22. Balkwill F, Mantovani A (2001) Inflammation and cancer: Back to Virchow? Lancet 357: 539-545.

23. Cho IR, Park JC, Park CH, Jo JH, Lee HJ, et al. (2014) Pre-treatment neutrophil to lymphocyte ratio as a prognostic marker to predict chemotherapeutic response and survival outcomes in metastatic advanced gastric cancer. Gastric Cancer 17: 703-710.

24. Halazun KJ, Aldoori A, Malik HZ, Al-Mukhtar A, Prasad KR, et al (2008) Elevated preoperative neutrophil to lymphocyte ratio predicts survival following hepatic resection for colorectal liver metastases. Eur J Surg Oncol 34: 55-60.

25. Oh BS, Jang JW, Kwon JH, You CR, Chung KW, et al. (2013) Prognostic value of $\mathrm{C}$-reactive protein and neutrophil-to-lymphocyte ratio in patients with hepatocellular carcinoma. BMC Cancer 13: 78

26. Hirashima M, Higuchi S, Sakamoto K, Nishiyama T, Okada H (1998) The ratio of neutrophils to lymphocytes and the phenotypes of neutrophils in patients with early gastric cancer. J Cancer Res Clin Oncol 124: 329-334. 
Citation: Zaghloul H, Abbas A (2017) The Role of Baseline Inflammatory Response Biomarkers in Predicting the Prognosis in No Metastatic Gastric Cancer Patients Treated with Preoperative Chemoradiation. Cancer Sci Ther 9: 608-616. doi: 10.4172/1948-5956.1000481

27. Yamanaka T, Matsumoto S, Teramukai S, Ishiwata R, Nagai Y, et al. (2007) The baseline ratio of neutrophils to lymphocytes is associated with patient prognosis in advanced gastric cancer. Oncology 73: 215-220.

28. Ajani JA, Winter K, Okawara GS, Donohue JH, Peter W, et al. (2006) Phase II trial of preoperative chemoradiation in patients with localized gastric adenocarcinoma (RTOG 9904): Quality of combined modality therapy and pathologic response. J Clin Oncol 24: 3953-3958.

29. Proctor MJ, McMillan DC, Morrison DS, Fletcher CD, Horgan PG, et al. (2012)A derived neutrophil to lymphocyte ratio predicts survival in patients with cancer. $\mathrm{Br} J$ Cancer 107: 695-699.

30. Crumley AB, McMillan DC, McKernan M, McDonald AC, Stuart RC (2006) Evaluation of an inflammation-based prognostic score in patients with inoperable gastro-oesophageal cancer. Br J Cancer 94: 637-641.

31. Satomi A, Murakami S, Ishida K, Mastuki M, Hashimoto T, et al. (1995) Significance of increased neutrophils in patients with advanced colorectal cancer. Acta Oncol 34: 69-73.

32. Kemal Y, Yucel I, Ekiz K, Demirag G, Yilmaz B, et al. (2014) Elevated serum neutrophil to lymphocyte and platelet to lymphocyte ratios could be useful in lung cancer diagnosis. Asian Pac J Cancer Prev 15: 2651-2654.

33. Deng Q, He B, Liu X, Yue J, Ying H, et al. (2015) Prognostic value of preoperative inflammatory response biomarkers in gastric cancer patients and the construction of a predictive model. J Transl Med 13: 66 .
34. Kusumanto YH, Dam WA, Hospers GA, Meijer C, Mulder NH (2003) Platelets and granulocytes, in particular the neutrophils, form important compartments for circulating vascular endothelial growth factor. Angiogenesis 6: 283-287.

35. Shamamian P, Schwartz JD, Pocock BJ, Monea S, Whiting D, et al. (2001) Activation of progelatinase A (MMP-2) by neutrophil elastase, cathepsin $\mathrm{G}$, and proteinase-3: A role for inflammatory cells in tumor invasion and angiogenesis. J Cell Physiol 189: 197-206.

36. Li L, Wang L, Song P, Geng X, Liang X, et al. (2014) Critical role of histone demethylase RBP2 in human gastric cancer angiogenesis. Mol Cancer 13: 81.

37. Zhang J, Wang P, Zhu J, Wang W, Yin J, et al. (2014) SPARC expression is negatively correlated with clinicopathological factors of gastric cancer and inhibits malignancy of gastric cancer cells. Oncol Rep 31: 2312-2320.

38. Muller I, Munder M, Kropf P, Hansch GM (2009) Polymorphonuclear neutrophils and T lymphocytes: Strange bedfellows or brothers in arms? Trends Immuno 30: 522-530.

39. Ohtani H (2007) Focus on TILs: Prognostic significance of tumor infiltrating lymphocytes in human colorectal cancer. Cancer Immun 7: 4.

40. Valenti V, Hernaandez-Lizoain JL, Martinez Requeira F, Gil A, Marti $\mathrm{P}$ et al. (2009) Analysis of postoperative morbidity in patients with gastric adenocarcinoma treated using a protocol of preoperative chemoradiotherapy and surgery. Cir Esp 86: 351-357. 